\title{
Sex-biased gene expression in the brown alga Fucus vesiculosus
}

\author{
Maria João F Martins, Catarina F Mota and Gareth A Pearson ${ }^{*}$
}

\begin{abstract}
Background: The fucoid brown algae (Heterokontophyta, Phaeophyceae) are increasingly the focus of ecological genetics, biodiversity, biogeography and speciation research. The molecular genetics underlying mating system variation, where repeated dioecious - hermaphrodite switches during evolution are recognized, and the molecular evolution of sex-related genes are key questions currently hampered by a lack of genomic information. We therefore undertook a comparative analysis of male and female reproductive tissue transcriptomes against a vegetative background during natural reproductive cycles in Fucus vesiculosus.

Results: Over 300 k reads were assembled and annotated against public protein databases including a brown alga. Compared with the vegetative tissue, photosynthetic and carbohydrate metabolism pathways were underexpressed, particularly in male tissue, while several pathways involved in genetic information processing and replication were over-expressed. Estimates of sex-biased gene (SBG) expression were higher for male (14\% of annotated orthologues) than female tissue (9\%) relative to the vegetative background. Mean expression levels and variance were also greater in male- than female-biased genes. Major female-biased genes were carbohydratemodifying enzymes with likely roles in zygote cell wall biogenesis and/or modification. Male-biased genes reflected distinct sperm development and function, and orthologues for signal perception (a phototropin), transduction (several kinases), and putatively flagella-localized proteins (including candidate gamete-recognition proteins) were uniquely expressed in males. Overall, the results suggest constraint on female-biased genes (possible pleiotropy), and less constrained male-biased genes, mostly associated with sperm-specific functions.

Conclusions: Our results support the growing contention that males possess a large array of genes regulating male fitness, broadly supporting findings in evolutionarily distant heterogametic animal models. This work identifies an annotated set of $F$. vesiculosus gene products that potentially regulate sexual reproduction and may contribute to prezygotic isolation, one essential step towards developing tools for a functional understanding of species isolation and differentiation.
\end{abstract}

Keywords: Brown algae, Fucus, Heterogametic sexes, Reproduction, Sex-biased genes, Sperm, Transcriptomics

\section{Background}

The evolution of sexual reproduction and sexual dimorphism has stimulated numerous studies at the molecular, genetic, ecological and behavioural levels [1-7]. Nevertheless, detailed molecular knowledge of the processes involved, and their role in delimiting species boundaries remains limited $[6,8]$. Genes that mediate sexual reproduction often evolve rapidly [2,9], contributing to prezygotic isolation and speciation [9-11]. However, in the early stages of reproductive isolation, ecological

\footnotetext{
* Correspondence: gpearson@ualg.pt

CCMAR,CIMAR-Laboratório Associado, Universidade do Algarve, Gambelas, Faro 8005-139, Portugal
}

divergence and niche-partitioning may contribute importantly to speciation without the direct involvement of genetic isolating mechanisms $[8,10,12,13]$.

Recent advances in high throughput transcriptomics now make possible the identification of genes that are differentially expressed in males and females (i.e. sexbiased genes, SBG), and inferences concerning the major evolutionary forces involved [4]. Two main patterns have emerged from studies largely focused on metazoans. First, genes contributing to reproductive isolation are fast-evolving, often driven by positive selection [14]. Second, SBG expression is widespread within the genome [4]. SBG are therefore likely to play an important

\section{Biomed Central}


role in reproduction, and thus be subjected to powerful selection (e.g. for species recognition, sexual selection; [9]). Interestingly, male-biased genes are generally more numerous than female-biased genes, more highly expressed on average, and often show evidence of higher divergence rates between species ([4]; but see $[15,16]$ ). Explanations for these phenomena usually focus on functional pleiotropy (i.e. additional non-reproductive roles) for female-biased genes, although intense male-male competition, or greater transcriptional activity in male germ tissue have also been suggested [17-19].

Brown algae (Heterokontophyta) are an independent multicellular lineage [20], and therefore an attractive model for reproductive and sexual evolution from a comparative genomic viewpoint. Fucoid brown seaweeds are oogamous broadcast spawning marine taxa that dominate temperate intertidal shores, with key ecological roles as ecosystem engineers and primary producers. The intertidal genus Fucus provides a particularly interesting system for studies of sexual dimorphism and reproductive isolation: recent diversification in the Atlantic within the last $5 \mathrm{My}$ [21] resulted in the evolution of well-separated clades, but also more recently diverged species and cryptic entities capable of hybridization [22-25]. Moreover, the mating system in fucoids is labile, and has undergone at least two independent transitions between dioecy and hermaphroditism within Fucus [21]. In externally fertilizing taxa, reproductive isolation may arise through both differential temporal and spatial timing of gamete release controlling prezygotic isolation [26-30], and the evolution of gametic incompability mechanisms $[9,31,32]$. The evolution of molecules involved in gamete-gamete recognition in free-spawning invertebrates have been widely studied, and rapidly-evolving proteins on gamete surfaces are of major importance in species recognition and speciation [9,32]. Egg and sperm proteins may be engaged in an arms race driven by several processes, from sexual conflict and sperm competition to reinforcement, frequencydependent selection, as well as ecological pressures [9], contributing to the build-up of post-mating prezygotic barriers and divergence leading to speciation.

Previous work has established basic cues and physiological mechanisms behind spawning synchrony in fucoids (e.g. [33-37]). Fucoid oogametes are released as gametangia from the reproductive tissue (receptacles) into the surrounding seawater on strictly semilunar cycles in marine intertidal environments [38-40], on favourable daytime low tides (approximately two-week intervals [30,37]), with interspecific variation in the daily pattern of gamete release recognized $[29,30]$. Similarly, earlier work has established the basic characteristics of gamete-gamete recognition in fucoids [41,42]. However, further progress in understanding variation underlying species differences has been hampered by the lack of available genomic information. The main aim of this study was to compare reproductive and vegetative transcriptomes in a natural population of male and female $F$. vesiculosus. The potential function of annotated ESTs showing sex-biased expression is discussed, with particular reference to differentially expressed metabolic pathways, signalling, and proteins potentially involved in gamete-gamete interactions. We found evidence for male-biased expression in F. vesiculosus related mainly to sperm-specific functions. Evidence for possible pleiotropy in the female is discussed.

\section{Methods}

\section{Plant collection, RNA extraction, cDNA synthesis and pyrosequencing}

A total of 20 adult reproductive $F$. vesiculosus $(10 \times$ males and $10 \times$ females) per sampling date were collected in 2008 at Praia Norte, Viana do Castelo, Portugal (4141'59"N; 851'19"W). Sampling was carried out beginning at sunrise on Sep 30 and Oct 9, corresponding to spring $(\mathrm{S})$ and neap $(\mathrm{N})$ tide phases, respectively. Sampling was performed in this way to increase transcript coverage during the semilunar reproductive cycles of gamete maturation and release. A receptacle (reproductive tissue; see Additional file 1) was taken from each individual and transverse sections were examined under a field microscope $(40 \times$ magnification) to identify and confirm the sexual phenotype. The remaining mature receptacles (separate pools of males and females) were briefly washed in seawater, wiped to remove surface epiphytes, and then flash-frozen in liquid nitrogen for transport to the laboratory. Vegetative tips (pooled from male and female algae) were treated in the same way. In the laboratory, tissues were lyophilized prior to RNA extraction following [43]. RNA was digested with RNase-free DNase (QIAGEN) for 15 minutes at room temperature and then purified with the RNeasy MIDI kit (ca. 1 mg total RNA; Qiagen). RNA concentration was estimated by spectrophotometry (GeneQuant, GE Healthcare); integrity was confirmed by running samples on a 1.2\% agarose gel.

Poly-A mRNA was isolated from total RNA (ca. $1 \mathrm{mg}$ ) using the Oligotex mRNA Midi kit (Qiagen). Double stranded cDNA was constructed using the SuperScript ${ }^{\circ}$ One-Cycle cDNA kit (Invitrogen), following the manufacturer's instructions. Four independent reactions were carried out for each of the six library samples: two using poly dT priming primers (Oligo $\mathrm{d}(\mathrm{T})_{25} \mathrm{VN}$ ) and two reactions using random primers $\left(\mathrm{N}_{15}\right)$. Double-stranded cDNA syntheses were purified using CyScribe GFX Purification Kit (GE Healthcare). A fluorometer was used to estimate DNA concentration (Picofluor, Turner Biosystems). The resulting cDNA (2-3 ug) was adjusted to $50 \mathrm{ng} / \mathrm{ul}$ for 454 pyrosequencing at the Max Planck Institute for Molecular Genetics, Berlin (GS FLX Titanium, Life Sciences, Roche). 


\section{Assembly and annotation}

Sequence quality assessment and trimming were performed using PRINSEQ [44] to remove short ( $\leq 50 \mathrm{bp}$ ) and low quality sequences (average phred score $\leq 20$ ), and tail regions (phred $\leq 20$, 5-base sliding window). Sequences from all six libraries that passed this step were combined to produce a single assembly using MIRA v. 3.0 [45]. Local BLASTN searches $\left(E \leq 10^{-10}\right)$ were performed against the Silva rRNA database (LSU and SSU parc, release 108) to identify rRNA. rRNA contigs and reads were filtered with a custom BioPython script. The remaining ESTs (contigs and singletons) were compared against the NCBI nonredundant protein database (nr) using the BLASTX algorithm $\left(\mathrm{E}\right.$-value $\left.\leq 10^{-4}\right)$. Putative protein sequences were extracted from BLASTX output, and compared against public protein databases (KEGG, Pfam) for further functional annotation. We used the tools and resources available at the CAMERA website (https://portal.camera.calit2. net/gridsphere/gridsphere), utilizing top hits in downstream analyses. A local database (MySQL) containing normalized reads (accounting for library size differences) and annotation information was built for searches and analyses. Additional file 2 provides a schematic outline of the assembly and analysis workflow. The original sequencing data (passing quality control) are available at the NCBI Sequence Read Archive (SRA), accession number SRR575725.

\section{Functional annotation and statistical analysis}

All orthology terms $(1,207)$ identified from BLASTX against the KEGG protein database were mapped onto KEGG pathways using the tools available at http://www. genome.jp/kegg/ko.html. Numbers of normalized reads/ library for each pathway were extracted from the local database; non-biologically meaningful pathways (e.g. human disease or other organism-specific pathways) were removed, and the data filtered for minimum KEGG terms/ pathway (threshold $\geq 5$ ) and total reads/pathway ( $\geq 200$ ). This reduced the total from over 150 to a core set of 40 . Library expression values (read counts) were compared using Fisher's exact test using IDEG6 software (Identification of Differentially Expressed Genes; [46]) with BenjaminiHochberg correction $(\alpha=0.05$; [47]): FS versus VS, MS versus VS, and MN versus VN. For graphical representation (MeV 4.8.1; [48]) data were expressed as $\log _{2}$ (read counts Library - read counts Library $_{2}$ ).

Contigs of $F$. vesiculosus were compared against the Ectocarpus proteome using BLASTX with an E-value cutoff of $\leq 10^{-10}$, and contigs matching the same Ectocarpus accession were combined to define an orthologous set of F. vesiculosus proteins (and hereafter referred to as genes). Differential expression (read counts/orthologue for each library, with a minimum cut-off of 20 reads/orthologue) between male, female and vegetative tissue was tested with Fisher's exact tests and Benjamini-Hochberg correction, and displayed graphically as $\log _{2}$ expression values. Distributions of expression values for vegetative-, male- and female-biased genes were compared using non-parametric Kolmogorov-Smirnov tests.

\section{Validation of gene expression by quantitative PCR}

Material for quantitative real-time PCR (qPCR) analysis was collected at Praia Norte, Viana do Castelo, Portugal. Sampling was carried out on rising tides in July 2011 during spring and neap tidal phases (as for the EST libraries), and an additional sample was taken two days after the gamete release peak, as determined in the field (see Figure 7c in [30]). Female and male individuals were sexed by examining sectioned receptacles under the microscope, and tagged in the field prior to sampling. Individual receptacles (female and male) were collected, while apical tips (vegetative tissue) were pooled; tissue was fast frozen in liquid nitrogen and stored at $-80^{\circ}$ before further analysis. qPCR analyses were performed according to previous work on F. vesiculosus [49]. Briefly, total RNA was extracted from lyophilized tissue from four individual female and four individual male receptacles; for nonreproductive tissue (Veg) pools of apical tips of at least four individuals (including both female and male material) were used. RNA concentration was estimated by spectrophotometry and integrity was confirmed by running samples on a $1.2 \%$ denaturing agarose gel. First strand synthesis was performed using SuperScript III (Invitrogen) from 1 ug of total RNA in two parallel $20-\mu \mathrm{l}$ reactions, which were then pooled. cDNAs quality were tested under standard PCR conditions (amplification conditions: $95^{\circ} \mathrm{C}$ for $2 \mathrm{~min}$ and then 35 cycles at $95^{\circ} \mathrm{C}$ for $30 \mathrm{~s}$, $65^{\circ} \mathrm{C}$ for $30 \mathrm{~s}$ and $68^{\circ} \mathrm{C}$ for $20 \mathrm{~s}$ ) and the product electrophoresed in a $2 \%$ agarose gel.

Primers for candidate genes were designed using the Primer3 web application (http://frodo.wi.mit.edu/), with a Tm of $68-70^{\circ} \mathrm{C}$ and an amplicon size between 100 and $250 \mathrm{bp}$. From an initial screening panel, eight candidate genes were selected for further qPCR analysis. Selection was carried out based on amplification quality and transcript expression pattern in the 454 dataset. qPCR was performed in a 96 well format, with triplicate amplifications and SYBR-green-based detection (Maxima SYBR Green/ROX, Fermentas in the Applied Biosystem stepone system). Reactions contained a 1:100 dilution of cDNA template and $0.5 \mu \mathrm{M}$ of primers in a total volume of $20 \mu$ l. Cycle parameters were $95^{\circ} \mathrm{C}$ for $2 \mathrm{~min}$ and then 45 cycles at $95^{\circ} \mathrm{C}$ for $10 \mathrm{~s}$ and $68^{\circ} \mathrm{C}$ for $30 \mathrm{~s}$. The amplification efficiency of each primer pair was calculated from dilution curves, using pooled cDNA from all treatment conditions as template. Relative expression was analysed with Applied Biosystems StepOne, using the $\Delta \Delta C T$ method corrected for amplification efficiency [50] and 
following [51] for applying multiple reference (housekeeping) genes: EF1d/b (elongation factor-1 $B$ beta) and SUMO3 (small ubiquitin-like modifier). A 1:100 dilution of the pooled cDNA from all treatment conditions was used as the internal reference.

\section{Results}

Annotation success and library comparisons

After adaptor trimming, quality assessment and removal of rRNA, 309,281 high quality ESTs were assembled into 41,918 contigs and 3,719 singletons (Table 1). The total number of contigs with a BLASTX hit E-value $\leq 10^{-4}$ was 17,170 (44.7\%) (Table 1). Annotation success by BLASTX was aided by the availability of the genome sequence for the brown alga E. siliculosus, which was the top hit species $(7,591$ contigs $=16.6 \%$, corresponding to 3,853 unique protein accessions). Second, with ca. two orders of magnitude fewer accessions was the Leguminosae Medicago truncatula (1,136 contigs with 39 unique accessions), followed by the diatom Thalassiosira oceanica (850 contigs with 43 unique accessions) and $F$. vesiculosus (385 contigs with 91 unique accessions). A preliminary analysis of expression values amongst the six libraries indicated potential contamination of the female neap (FN) library by male tissue. After confirmation by qPCR tests (data not shown) the FN library was not considered further, reducing the assembly to 241,870 reads in 38,415 contigs and 2,761 singletons. Differences in expression between spring and neap tidal samples for male and vegetative tissue were low (35 and 25 genes, respectively: Additional file 3). Kolmogorov-Smirnov tests indicated that the distributions of significant DE terms did not differ between these tissue types (data not shown). Further analysis was therefore confined to the spring tide libraries.

A relatively small subset of contigs were expressed in all tissues $(1,809,16 \%)$, but accounted for $64.5 \%$ of reads (Figure 1a). Many small contigs were assigned uniquely to individual tissues. Pairwise comparisons indicated that male and female tissues were the most differentiated,

Table 1 Summary statistics of 454 assembly after trimming

\begin{tabular}{llllll}
\hline Library & reads & length (bp) & contigs & N50 (bp) & Annotated (\%) \\
\hline FN** & 67,411 & 271.8 & & & \\
FS & 30,316 & 283.4 & & & \\
MN & 56,978 & 277.3 & & & \\
MS & 37,717 & 271.1 & & & \\
VN & 74,765 & 266.9 & & & $17,170(44.7)$ \\
VS & 42,094 & 268.3 & & & \\
Total & 309,281 & 272.2 & 41,918 & 544 & 1
\end{tabular}

$F$ female, $M$ male and $V$ vegetative tissue; $N$ neap tide, $S$ spring tide samples. *BLASTX; $\mathrm{E} \leq 10^{-4}$.

**Possible contamination with male tissue - not analysed further. a)

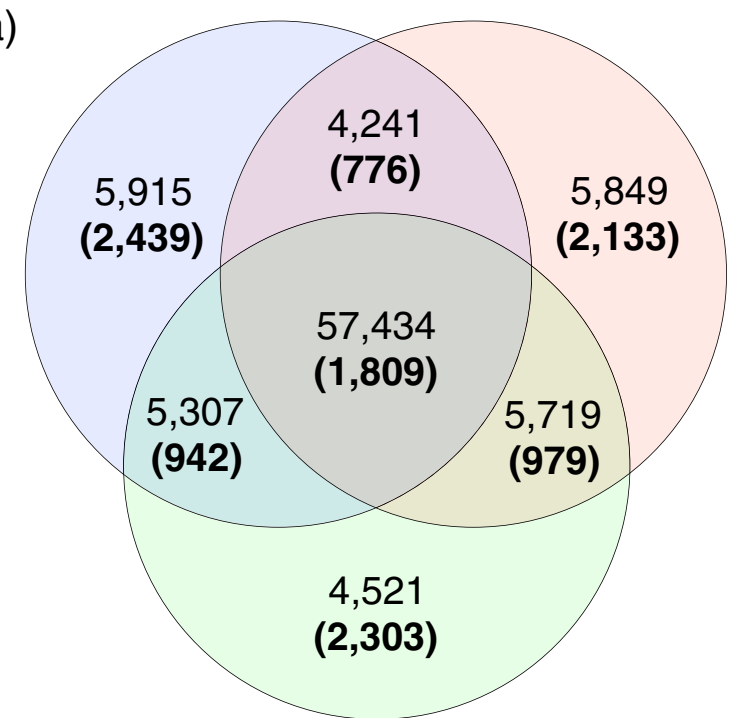

b)

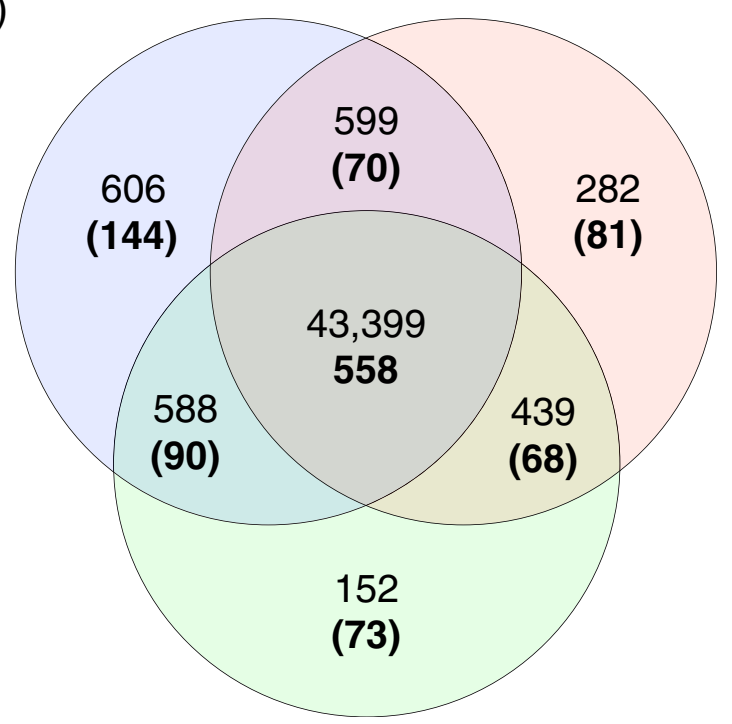

Figure 1 Venn diagrams summarising the distribution of sequence reads between tissue types. Data are from spring tide libraries for male (blue), female (pink) and vegetative tissue (green) showing a) normalized read counts and number of contigs (bold in parentheses) for BLASTx annotated dataset $\left(E \leq 10^{-4}\right)$, and $\left.\mathbf{b}\right)$ normalized read counts and number of Kegg orthology terms (bold in parentheses; $\mathrm{E} \leq 10^{-6}$ ).

sharing the fewest contigs and reads (Figure 1a). At the functional level, a core set of 558 Kegg terms (>50\%) were common to all tissues, accounting for $94 \%$ of annotated reads. Male tissue showed the greatest number of unique Kegg orthology terms (13\%) and corresponding numbers of reads (Figure 1b).

\section{Trancriptome functional analysis}

A total of 1,084 KEGG orthology terms were identified in the dataset (FS, MS, VS; see Additional file 4 for the 
list of KEGG terms and Additional file 5 for the list of Pfams identified), and were mapped onto 123 pathways (KEGG ko; list available as Additional file 6). 'Translation' was the most common functional class, represented mostly by the biochemical pathway 'Ribosome' (ko03010). The number of transcripts assigned to this pathway is about 7.5x higher than the second most expressed pathway, 'Photosynthesis' (ko00195), class 'Metabolism'.

Analysis of KEGG pathway expression showed that 32 of the 40 core pathways had significant differences in transcript representation (Figure 2). Relative to vegetative tissue, both female and male sexual tissues were under-represented for transcripts belonging to energy metabolism pathways, including photosynthetic carbon fixation (ko00710) and antennae proteins (ko00196). Under-expression of nitrogen metabolism (ko00910) was mainly due to fewer transcripts for carbonic anhydrases (Additional file 6), which are likely to mediate inorganic carbon acquisition in brown algae [52-54]. These differences were most obvious in the male tissue (Figure 2), also supported by the observation that transcripts for photosynthesis (ko00195; i.e. generation of reducing power in the light reactions) were under-expressed in males, but not in females. Several pathways for carbohydrate metabolism were also under-expressed in both sexes; glycolysis and gluconeogenesis (ko00010), pentose phosphate pathway (ko00030), fructose and mannose metabolism (ko00051) (Figure 2). Under-expression of transcripts for peroxisome (ko04146) and PPAR signaling (ko03320) pathways in sexual tissues was also seen. However, the main peroxisomal transcripts affected are involved in free radical detoxification and/or redox signalling (peroxiredoxin and Mpv17), rather than lipid homeostasis. Furthermore, peroxisomal, rather than chloroplast or mitochondrial targeting of these transcripts could not be confirmed. Similarly, downregulation of the peroxisome proliferator-activated receptor (PPAR) pathway was due almost entirely to underexpression of acyl-CoA-binding protein (K08762), which binds medium- and long-chain acyl-CoA esters and has multiple cellular roles.

Male-biased expression of the ribosome pathway, as well as RNA transport (ko03013), RNA degradation (ko03018) and mRNA surveillance (ko03015), RNA polymerase (ko03020), spliceosome (ko03040), nucleotide

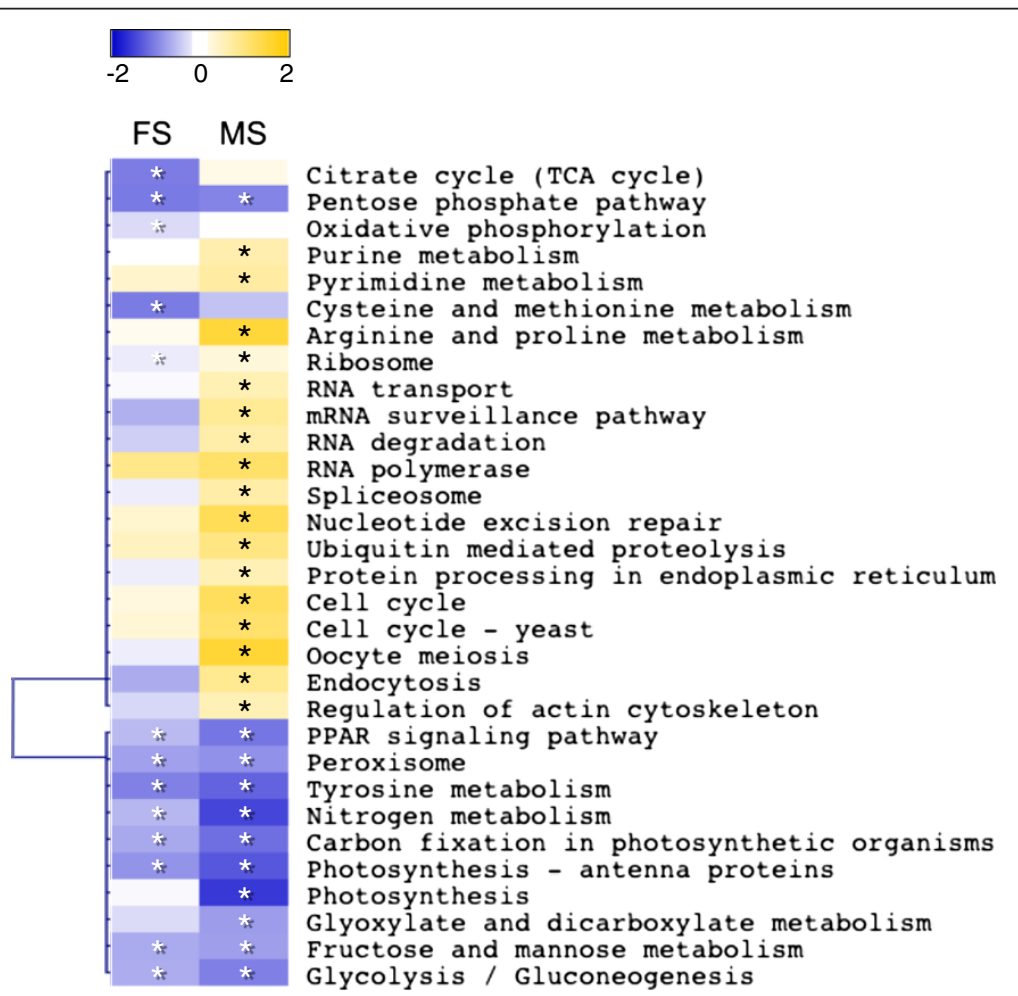

Figure 2 Heatmap of differential expression in KEGG pathways between sexual and vegetative tissue. Pixels represent Log 2 (sexual - vegetative) read counts for a pathway. Significantly different pairwise expressions were identified by Fisher's exact tests after Benjamini-Hochberg adjustment $(P<0.05)$ between sexual and vegetative tissue collected at the Spring reproductive cycle, i.e. F vs Veg, and $M$ vs Veg. Blue indicate under-expression and yellow over-expression of sexual relative to vegetative tissue. Asterisks indicate significant pairwise comparisons within a pathway: in white- sex under-regulated pathway compared to the vegetative tissue; in black - male- or female up-regulated pathway relative to the vegetative tissue. 
excision repair (ko03420), protein processing in the endoplasmic reticulum (ko04141), ubiquitin mediated proteolysis (ko04120), oocyte meiosis (ko04114) and cell-cycle pathways (ko04110, ko04111) is indicative of actively differentiating and replicating cells (Figure 2, Additional file 6).

\section{Comparative sex-biased gene expression}

We compared the expression of male and female sexbiased genes in the spring tide phase of the reproductive cycle, when mature gametangia are present, but gamete release is minimal or null [30]. Expression in female and male sexual tissue revealed 28 female and 92 male overexpressed genes (Figure 3a). The pattern of greater malebiased expression was confirmed by comparison of sexual tissues against the vegetative background, where $27 \mathrm{fe}$ male and 91 male over-expressed genes were identified (Figure 3b, c). More genes were under-expressed than over-expressed in females (i.e. over-expressed in the vegetative background: 76 versus 27), while numbers were similar in male tissue ( 89 versus 91 ).

The median and variance of expression value distributions of SBG were compared between female and male tissue using Kolmogorov-Smirnov tests (Figure 2d). Distributions for female and male SBG differed significantly $(\mathrm{D}=0.382 ; P=0.003$; Figure $3 \mathrm{~d})$. Both the median expression (21 versus 58.5 for females and males) and the average deviation from the median (26.9 versus 49.8) were greater for male-biased genes. Differences in distributions between SBG and vegetative background were also found $(P=0.002$ for males and $P=0.001$ for females), and were explained mainly by elevated variance in males and reduced median in females (Figure 2e, f).

\section{Proteins putatively associated with sexual differentiation}

After mapping of $F$. vesiculosus genes to Ectocarpus orthologues, a single female-specific gene was identified: a member of the mannuronan C-5-epimerase gene
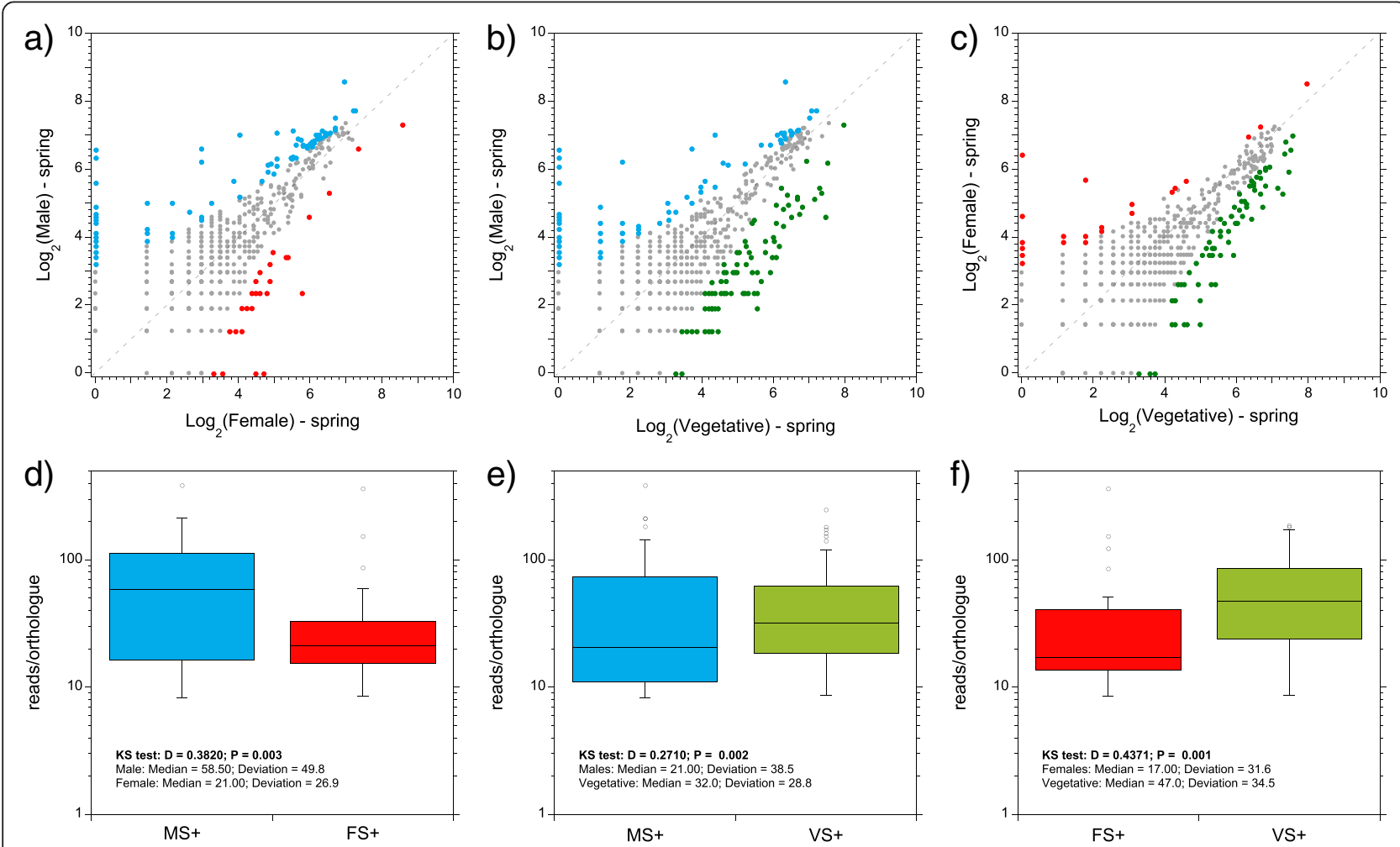

Figure 3 Scatter- and boxplots comparing tissue-specific gene expression in the spring tidal phase. Scatter plots of gene expression (as $\log _{2}[$ reads]) in a) female versus male tissue, b) vegetative versus male tissue, and $\mathbf{c}$ ) vegetative versus female tissue. Each point on the plots represents a $F$. vesiculosus gene orthologue defined by mapping contigs to the $E$. siliculosus proteome using BLASTX. Only genes with $\geq 20$ reads were analysed and are shown on the plots (total =693). Points in green, red and blue indicate statistically significant over-expression in vegetative female and male tissue, respectively (Fisher's exact tests with Benjamini-Hochberg adjustment; $P<0.05$ ). Points in grey do not differ in expression between tissue types. Boxplots (lower panel) corresponding to each scatter plot show distributions of significant expression values as reads/ orthologue for sets of sex- and vegetatively-biased genes: $\mathbf{d}$ ) female versus male tissue, e) male versus vegetative tissue, and f) female versus vegetative tissue. MS+, FS+, and VS + = over-expressed in male, female, and vegetative spring tide libraries, respectively. The result of Kolmogorov-Smirnov tests on the distributions are summarized on each plot. 
family. This gene catalyses the final step of alginate biosynthesis [55] (Table 2). Another female-biased gene was also identified, and related to carbohydrate modification with a likely role in cell wall biogenesis (chondroitinD-glucuronate 5-epimerase). A gene encoding aquaporin (APQ1; K09864) that was over-expressed in female tissue in spring tide library was also over-expressed in males in the neap tide library, and was barely detectable in either vegetative tissue library (Table 2; Additional file 4).

In contrast to females, many more male-biased or malespecific genes were identified (Table 2). Amongst malespecific terms, signalling-related genes were conspicuously over-represented. Most striking was a mitogen activated protein kinase (MAP2K; K04368), a cAMP-dependent protein kinase regulator (PRKAR; K04739), a PAS-PAC histidine kinase and putative blue-light photoreceptor, calmodulin genes and a $\mathrm{Ca}^{2+} /$ calmodulin-dependent protein kinase (CaMK; K00908). This provides a general picture of male tissue as very active in signalling for a potentially diverse range of cellular processes. The over-expression of dynein-related molecular motor proteins (K10410, K10411), tenascin-like Sig (sexually induced) genes and creatine kinases involved in energy storage and release are likely related to specific flagella localization and functions. We also identified male-biased genes for histones, centrin, as well as $\alpha$ - and $\beta$-tubulins (Table 2).

\section{Gene expression validation by qPCR}

Quantitative RT-PCR analysis of independent samples of sexual and vegetative tissues confirmed the results obtained by pyrosequencing. Seven male-biased and one female-biased transcripts were selected after tests for amplification efficiency. The specific contig and primer sequences are given in Additional file 7. In agreement with pyrosequencing results, alpha-tubulin (TUBA) and centrin were confirmed as male-biased, with low but detectable expression in non-male tissue (Figure 4a,c), while a betatubulin isoform, a Mec-17 domain protein (pfam05301; touch receptor protein), and 2 tenascin-like proteins homologous to sexually induced (Sig) genes 1 and 3 from the diatom Thalassiosira weissflogii were male-specific (Figure 4d,e,f). A cAMP-dependent protein kinase regulatory subunit (PKA), which was only detected in male libraries, was highly male-biased in qPCR tests, with $>20$ fold lower expression in females and below detection limits in vegetative tissue (Figure $4 \mathrm{~g}$ ). Variation in expression within the tidal cycle was less clear, although increased expression in males at neap tide for some transcripts (centrin, PKA) agrees with pyrosequencing results. Finally, the female-biased expression of a mannuronan C5-epimerase was also confirmed (Figure 4h). Interestingly, expression of this transcript was not detected in the postneap sample (i.e., following gamete release) (Figure $4 \mathrm{~h}$ ), suggesting that it may be localized to mature oogonia.

\section{Discussion}

This study provides the first transcriptomic analysis of expression variation in reproductive tissues for a brown alga during natural reproductive cycles. We show that primary energy and carbohydrate metabolic pathways are under-represented in sexual (male and female) tissues. Differentiation is most clearly apparent in male tissue (Figure 2). At the same time, pathways for genetic information processing and cell-cycle related processes were over-represented in males. Expression analysis of protein annotations confirmed the view that male-biased expression involved greater numbers of gene products, and that variance in expression was greater for malethan for female-biased genes. Moreover, specific transcripts were found in male receptacles that were not detected in females, consistent with sperm-specific developmental and signaling pathways. Finally, our analyses (confirmed by RT-qPCR) revealed several strongly sex-biased or sex-specific transcripts that are potential targets for expression and/or sequence analysis for studying ecological and evolutionary processes in recently diverged sister species of Fucus.

\section{Pathway analysis reflects sex-specific variation in metabolism and cell proliferation}

Primary metabolism for energy and carbohydrate pathways differed between the sexes and between sexual and vegetative tissue, presumably reflecting functional constraints and trade-offs associated with different developmental programs and sexual phenotype. Receptacle photosynthetic rates are reported to be ca. $50 \%$ lower than in non-reproductive tissue in F. serratus [56], although no information on sexspecific variation is available. At the transcriptional level, male under-expression of photosynthesis-related pathways exceeded that in females, particularly for light energy capture (antennae proteins) and photosynthetic electron transport (neither of which differed between female and vegetative tissue at spring tide). This could reflect greater female investment in gamete provisioning.

While respiratory pathways were under-expressed in sexual tissue generally, neither oxidative phosphorylation nor the citrate (TCA) cycle in males were significantly different from vegetative tissue during the spring tide phase of reproduction, the period when energy expenditure in spermatogenesis, and the maturation of anteridia for release on the following neap tide cycle should be greatest. The fucoid sperm is the only motile phase of the life cycle, showing a heterokont biflagellated cell pattern [57]. Sperm flagella have two main functions requiring high energy consumption: swimming and mediation of gamete-gamete interactions during fertilization (via the anterior mastigoneme-bearing flagellum; [58]). Transcripts for creatine and arginine kinases (arginine and proline metabolism pathway; Additional file 4), were also 
Table 2 Selected female- and male-biased $F$. vesiculosus genes, based on orthology to $E$. siliculosus proteins

\begin{tabular}{|c|c|c|c|c|c|c|c|c|}
\hline Description & No. contigs & $\begin{array}{l}\text { E. siliculosus } \\
\text { Orthologue }\end{array}$ & $F$ & $M$ & Veg & KEGG & Pfam & GO \\
\hline \multicolumn{9}{|l|}{ Female-biased: } \\
\hline $\begin{array}{l}\text { Glucosylceramidase (family GH30)/ Lectin } \\
\text { domain-like }\end{array}$ & 2 & CBN79893 & 51 & 4 & 3 & & $\begin{array}{l}\text { PF02055; } \\
\text { PF14200 }\end{array}$ & \\
\hline Mannuronan C-5-epimerase 4 & 1 & CBN79256 & 24 & - & - & K00771 & & 30158 \\
\hline Chondroitin-glucuronate 5-epimerase & 2 & CBJ29234 & 26 & 4 & 7 & K01795 & PF00124 & \\
\hline Aquaporin PIP-type & 2 & CBN74001 & 15 & 3 & 4 & K09864 & PF00230 & 15250 \\
\hline Photosystem II reaction centre protein D1/psbA & 66 & CAV31176 & 930 & 291 & 807 & K02703 & & \\
\hline Imm upregulated 3 & 24 & CBN74763 & 378 & 157 & 254 & & & \\
\hline \multicolumn{9}{|l|}{ Male-biased: } \\
\hline Transcription elongation factor Elf1 like & 1 & CBJ25475 & 15 & 36 & 11 & & PF05129 & \\
\hline Touch receptor neuron protein Mec-17 & 2 & CBJ49002 & 2 & 11 & - & & PF05301 & \\
\hline Conserved unknown protein (Josephin) & 1 & CBJ28700 & - & 22 & - & & PF02099 & \\
\hline BT1 family, putative pteridine transporter & 2 & CBN78031 & 14 & 49 & 16 & & PF03092 & \\
\hline Cystathionine gamma-lyase & 2 & CBN75996 & - & 8 & - & K00810 & PF01053 & $3962 ; 5843$ \\
\hline $\begin{array}{l}\text { 1-phosphatidylinositol-4-phosphate 5-kinase/ } \\
\text { radial spoke }\end{array}$ & 2 & CBN78497 & - & 5 & - & K00889 & & 16308 \\
\hline $\mathrm{Ca} 2+/$ calmodulin-dependent protein kinase & 1 & CBN78721 & - & 8 & - & K00908 & & $4684 ; 4685$ \\
\hline Creatine kinase & 4 & CBN74482 & - & 48 & - & K00933 & $\begin{array}{l}\text { PF02807; } \\
\text { PF00217 }\end{array}$ & 5843 \\
\hline Creatine kinase & 4 & CBN77192 & - & 21 & - & K00933 & PF00217 & $4111 ; 5842$ \\
\hline $\begin{array}{l}\text { PAS/PAC histidine kinase; putative blue } \\
\text { light receptor }\end{array}$ & 6 & CBJ26132 & - & 30 & - & K02489 & PF00989 & 4054 \\
\hline $\begin{array}{l}\text { F-type } \mathrm{H}+\text {-transporting ATPase } \\
\text { subunit delta }\end{array}$ & 2 & CBJ32297 & 2 & 18 & 4 & K02134 & PF02823 & 5843 \\
\hline Calmodulin & 4 & CBN74598 & - & 25 & - & K02183 & & 5842 \\
\hline Calmodulin & 1 & CBN80105 & - & 14 & - & K02183 & & 5842 \\
\hline Mitogen-activated protein kinase & 3 & CBJ31415 & - & 94 & - & K04368 & PF00069 & 5842 \\
\hline cAMP-dependent protein kinase regulator & 4 & CBJ34040 & - & 22 & - & K04739 & PF00027 & $5842 ; 8603$ \\
\hline Proliferating cell nuclear antigen & 4 & CBJ25497 & 3 & 18 & - & K04802 & $\begin{array}{l}\text { PF00705; } \\
\text { PF02747 }\end{array}$ & \\
\hline Voltage dependent anion channel & 3 & CBN78926 & 5 & 33 & 12 & K05862 & PF01459 & 5842 \\
\hline $\begin{array}{l}\text { Tubular mastigoneme-related protein } \\
\text { (Sig)/ tenascin }\end{array}$ & 3 & CBJ28331 & - & 14 & - & K06252 & PF07974 & \\
\hline $\begin{array}{l}\text { SecE/Sec61-gamma subunit protein } \\
\text { translocation complex }\end{array}$ & 17 & CBN73851 & 85 & 141 & 103 & K07342 & PF00584 & $\begin{array}{l}5842 ; 5843 ; \\
5874\end{array}$ \\
\hline Alpha tubulin & 24 & CBN77373 & 122 & 387 & 80 & K07374 & $\begin{array}{l}\text { PF03953; } \\
\text { PF00091 }\end{array}$ & $\begin{array}{l}4111 ; 5842 ; \\
5843\end{array}$ \\
\hline Beta tubulin & 4 & CBJ26064 & - & 14 & - & K07375 & PF03953 & 5842 \\
\hline Beta tubulin & 3 & CBN79446 & 15 & 128 & 20 & K07375 & PF03953 & 5843 \\
\hline $\begin{array}{l}\text { Dynein flagellar outer dynein arm } \\
\text { light chain }\end{array}$ & 1 & CBJ48309 & - & 8 & - & K10411 & & 5843 \\
\hline Putative flagellar outer dynein arm light chain & 2 & CBJ27240 & - & 16 & 2 & K10419 & PF03259 & 5842 \\
\hline Centrin & 3 & CBN74045 & - & 29 & 1 & K10840 & PF00036 & $\begin{array}{l}4054 ; 5842 ; \\
8603\end{array}$ \\
\hline Centrin & 2 & CBN79657 & - & 8 & - & K10840 & & $5842 ; 5843$ \\
\hline Histone H2A & 5 & CBJ31989 & 7 & 74 & 2 & K11251 & PF00125 & $\begin{array}{l}5842 ; 5843 ; \\
5874\end{array}$ \\
\hline Histone $\mathrm{H} 2 \mathrm{~A}$ & 2 & CBJ32072 & 7 & 96 & 12 & K11251 & PF00125 & 5842 \\
\hline
\end{tabular}


Table 2 Selected female- and male-biased $\boldsymbol{F}$. vesiculosus genes, based on orthology to $E$. siliculosus proteins (Continued)

\begin{tabular}{|c|c|c|c|c|c|c|c|c|}
\hline Histone H2B & 13 & CBJ32076 & 2 & 31 & 7 & K11252 & PF00125 & $\begin{array}{l}5842 ; 5843 ; \\
5874\end{array}$ \\
\hline Histone H3 & 5 & CBN79887 & 32 & 135 & 73 & K11253 & PF00125 & $\begin{array}{l}5842 ; 5843 ; \\
5874\end{array}$ \\
\hline AP-2 complex subunit sigma-1 & 1 & CBN77646 & 2 & 14 & 1 & K11827 & PF01217 & 5843 \\
\hline Herpes virus major outer envelope glycoprotein & 5 & CBN77192 & - & 81 & - & & PF05109 & \\
\hline
\end{tabular}

The table shows the number of $F$. vesiculosus contigs mapping (BLASTX, E-value $\leq 10^{-10}$ ) to an $E$. siliculosus protein; descriptions are based on the accession and/or annotations in the KEGG, Pfam and GO databases. Expression is shown for Spring Female (F), Male (M) and Vegetative (Veg) libraries (as normalized reads; see Results for more details).

highly expressed in males, and virtually absent from other tissues. Phosphocreatine and phosphoarginine are storage molecules forming an energy reservoir from which ATP can be rapidly generated to replenish cellular energy balance in highly active cells.

The estimated sperm-egg ratio is 400:1 in F. vesiculosus [23], so elevated levels of cell cycle activity and associated processes during gametogenesis in male tissue may arise simply because a greater number of cells (and pro- portion of mRNA) in the tissue sample are affected. Cell cycle and oocyte meiosis pathways were overexpressed uniquely in males, and were accompanied by male over-expression of pathways involved in transcription (RNA polymerase, spliceosome), translation (ribosome, mRNA surveillance), protein folding, sorting and degradation (ubiquitin-mediated proteolysis, protein processing in the endoplasmic reticulum, RNA degradation), and replication and repair (nucleotide excision and repair).
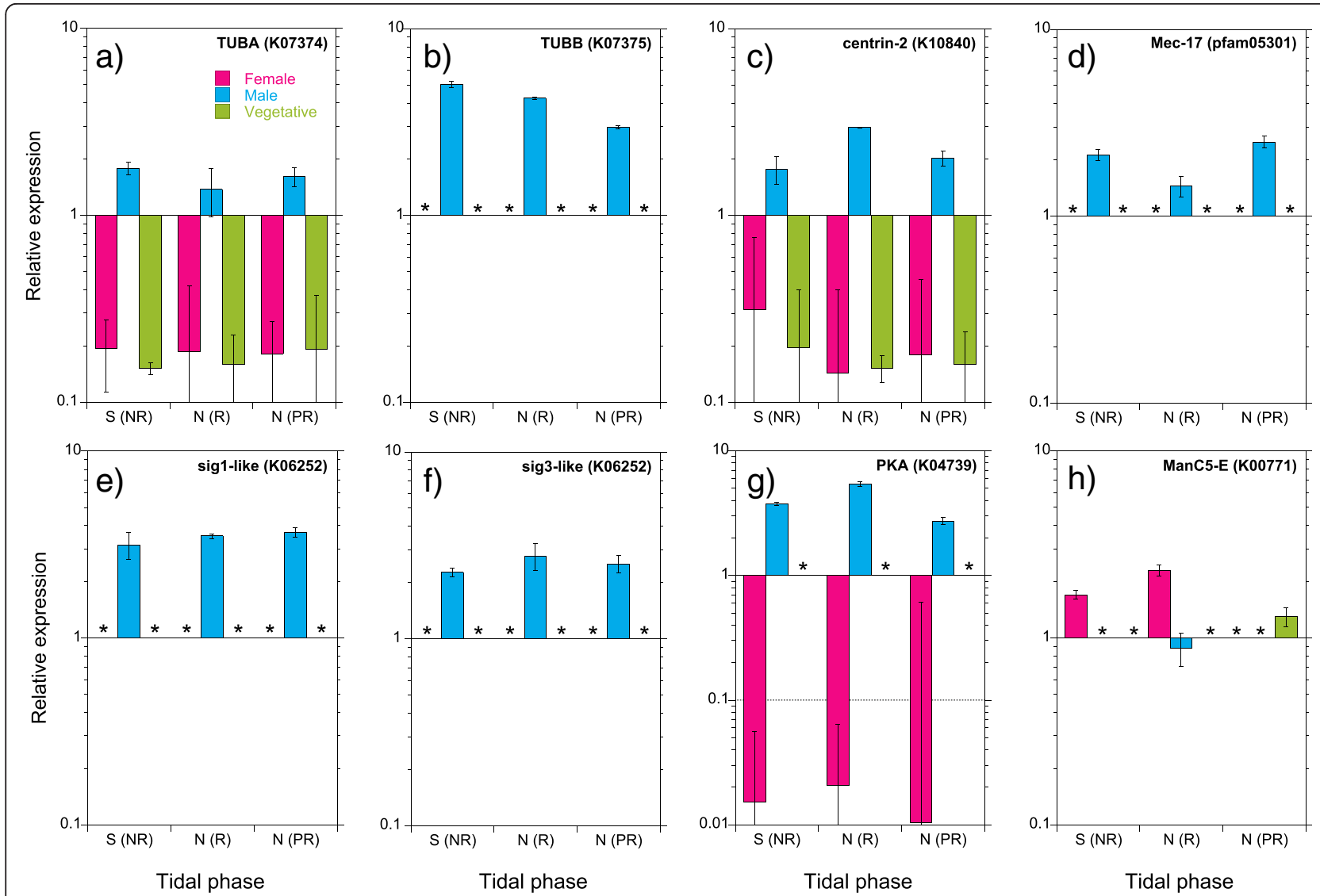

Figure 4 RT-qPCR analysis of gene expression for selected male- and female-biased genes. Values are relative expression (fold-change plotted on a Log scale, relative to a pool of all samples normalized to housekeepers EFd/b1 and SUMO3) for female (red), male (blue) and vegetative (green) tissue collected from the field during spring tide (S), and neap (N) tides. Genes were annotated based on homology to Ectocarpus siliculosus proteins, KEGG orthology, and/or Pfam databases; a) TUBA (a-tubulin), b) TUBB ( $\beta$-tubulin), c) centrin-2, d) Mec-17-like protein (mechanosensitive touch receptor), e) Sig1 (diatom sex-induced gene homologue), f) Sig3, g) PKA (protein kinase A), and h) ManC5-E (mannuronan C5 epimerase). Asterisks indicate expression values below the cut-off for detection. (NR) = no gamete release, $(R)=$ gamete release, and $(\mathrm{PR})=$ post gamete release in the field. See Results for descriptions of gene targets. 
Overall, pathway analysis strongly reflects higher replicative activity in male relative to female reproductive tissue.

\section{Patterns of sex-biased gene expression}

High throughput sequencing technologies have increased our focus on sex-biased gene expression with the realization that a large proportion of the transcriptome in many organisms shows distinct patterns of male and female expression [4,16,59-61]. Sexual dimorphism occurs against an almost identical genomic background, implying that the majority of sexually dimorphic traits may experience differential, or even conflicting, selection pressure in males and females [4]. Several studies have identified demasculinization (under-representation of male-biased genes) and/or femininization (greater numbers of femalebiased genes) on $\mathrm{X}$ chromosomes in organisms with heterogametic male (XY) chromosomes ([4,19,62-66]; see also [15] for ZW sex determination in birds). However, the evolutionary dynamics of demasculinization may be complex, with evidence in Drosophila that recent malebiased genes may initially accumulate on the $\mathrm{X}$ chromosome and be lost over time [67].

This is the first dataset to our knowledge that can begin to address the question of sex-biased gene expression in brown algae, an independent multicellular lineage [20]. Despite a relatively low sequencing depth, we found more genes over-expressed in males than in females (ca. 13\% versus $4 \%$ of the total), and that both the mean and variance of expression were significantly greater in males. We currently know little about sex determination in brown algae other than that it is genetically based [68], although the recent discovery of a nonrecombining chromosomal locus in Ectocarpus promises progress in this area (SM Coelho and JM Cock, pers commun; [69]). Since most evidence from the literature suggests greater sex-biased expression in the heterogametic sex (males in Drosophila, Silene, females in birds), it will be interesting to further study sex-determination and the occurrence or not of heterogametic sex in Fucus.

\section{Sex-biased gene expression in females and pleiotropic constraint}

Relatively few over-expressed female annotations were identified in our dataset. Overall, our data are consistent with widespread pleiotropic effects in female-effect genes $[1,17,18,59]$.

The three clearest examples of female-biased genes are all carbohydrate-modifying enzymes. Two were epimerases - mannuronan C-5-epimerase and chondroitin-Dglucuronate 5-epimerase (COG0451) - with roles in cell wall biogenesis and/or modification. Mannuronan C-5epimerase is a multigene family in brown algae [55], performing the final step in alginic acid biosynthesis that is critical for the formation of the alginate-rich brown algal cell wall. Of the 13 contigs in our dataset with top Blast hits to 12 predicted mannuronan C-5-epimerase proteins in Ectocarpus, three were female-unique, and one was expressed at a relatively higher level in female reproductive tissue. A third transcript encodes a homologue to an Ectocarpus glucosylceramidase. This transcript(s) contained both an O-glycosyl hydrolase (hydrolysis of glycosidic bonds) and a lectin-like (carbohydrate-binding) domain. It seems unlikely that this gene product participates directly in the fertilization process, as the presence of lectin domains on female gamete recognition proteins runs contrary to what is known about gamete recognition in Fucus, or invertebrates, where spermlocalized glycoproteins bind carbohydrate ligands on the egg $[31,41,42,70]$. The functional significance of this gene therefore remains to be seen.

Gametangial expulsion from fucoid receptacles is a rapid (min) process [34], mediated by osmotic adjustments associated with periods of $\mathrm{K}^{+}$and $\mathrm{Cl}^{-}$efflux from oogonia into the conceptacle extra-cellular matrix (ECM) [36]. Subsequent swelling of the ECM and/or expansion of anchoring gametangial stalk cells may be key events driving gametangial release. We identified a sex-biased (FS and $\mathrm{MN}$ ) aquaporin-1 that could potentially play a key role in controlling rapid movements of water between cells and the ECM. Although previous work with inhibitors provided evidence for the involvement of $\mathrm{K}^{+}$uptake, slowtype anion channels, and tyrosine phosphorylation in gamete expulsion [34], our transcript profiles failed to reveal candidate genes with potential roles in these processes in sexual tissue.

\section{Male-biased and male-specific patterns of gene expression: putative sperm signal transduction and flagella function}

The number of male-biased and -unique annotations confirms male reproductive tissue as being highly differentiated compared with either female or vegetative tissue. The majority of these gene products are likely components of the flagella (e.g., tubulin, dynein), or flagella basal bodies (e.g. centrin; [71]). In addition, a number of genes with known functions in signal perception and transduction and/or cytoskeletal regulation were male-specific. A phototropin-like blue light receptor was uniquely expressed in males, with homology to an Ectocarpus PAC/PAS sensor histidine kinase and green algal phototropins. Fucoid sperm are negatively phototactic, and this gene is a prime candidate for the sperm photoreceptor. The absence of any transcript for a putative blue-light receptor in female tissue (including putative opsin-like proteins; [72]) is curious, since photopolarization by blue-light is one of the first axis-forming responses of the zygote after fertilization 
$[73,74]$. It remains possible however, that expression of some female genes at the neap tide (gamete-release) phase of the reproductive cycle are under-represented in the spring tide library, when numbers of mature oogonia may be lower [30,34].

Eukaryotic cilia and flagella use both cyclic adenosine monophosphate (cAMP) and calcium as second messengers to regulate the beating of dynein-driven microtubules in the axomene [75]. We detected a male-specific cAMPdependent protein kinase (PKA) regulatory subunit. PKA is known to play a key role in mammalian sperm capacitation [76] via the cAMP/PKA signaling pathway. cAMPdependent phosphorylation of flagella proteins, particularly axonemal dynein, is essential for the initiation and maintenance of mammalian sperm motility, with PKA the likely downstream kinase responsible for phosphorylation $[77,78]$. Therefore, although we were unable to confirm the presence of adenylate cyclase or potential PKA-anchoring proteins in our dataset, the male-specific expression of PKA regulatory subunit hints at shared components in sperm signalling pathways in brown algal and mammalian systems.

Male transcriptome data revealed the expression of a specific CaMK, a male-specific calmodulin isoform, and a dynein-light chain (both the latter with CaM EF-hand $\mathrm{Ca}^{2+}$-binding domains). Calcium and $\mathrm{Ca}^{2+}$ signalling play a central role in flagella function and sperm motility from mammals to green algae $[79,80]$, with evidence for the involvement of calmodulin (CaM) and $\mathrm{Ca}^{2+} / \mathrm{CaM}$-dependent kinases (CaMK) that modulate dynein activity in the axoneme [81-83]. The identification of a male-specific 1phosphatidylinositol-4-phosphate 5-kinase (PIP5K) annotated as a axonemal radial spoke protein in Ectocarpus may further indicate a link between the phosphatidylinositol signalling pathway, releasing $\mathrm{Ca}^{2+}$ from intracellular stores, with $\mathrm{Ca}^{2+}$ induced modulation of flagella activity in sperm.

Finally, a highly over-expressed mitogen activated protein kinase kinase (MAPKK) was identified in male reproductive tissue. The MAP kinase pathway has many important roles mainly in the transduction of extracellular signals, particularly in plant stress signalling pathways [84], but also more generally in the control of cell growth, death, proliferation and differentiation. In the context of male-specific expression, MAP kinases are implicated in the control of flagella development in Chlamydomonas [85].

\section{Male-specific candidate genes for gamete-gamete interactions}

Homologues to the sexually induced protein (Sig) family, first identified in Thalassiosira weissflogii by Armbrust [86], showed male-specific expression in Fucus vesiculosus. Based on homology with Ectocarpus predicted protein sequences, four independent transcripts were identified, with sequence similarities to $T$. weissflogii Sig1-3. The most highly expressed member was Sig1-like and contained cysteine-rich epidermal growth factor (EGF)-like domains and similarity to extracellular tenascin-like glycoproteins involved in vertebrate cell adhesion $[87,88]$. Interestingly, some Ectocarpus homologues are annotated as tubular mastigoneme proteins of the anterior flagellum. Mastigonemes are tubular hairs present on the anterior flagellum of heterokonts (but lacking in diatoms) that play an important role in establishing sexual contact in Ectocarpus [58]. A second group of five male-specific contigs homologous to Ectocarpus CBN79192, and with limited homology to Herpes virus major outer envelope glycoprotein (Herpes_BLLF1; Pfam05109) could also be involved in cell-cell interactions.

After earlier work established some of the characteristics of sperm-egg recognition in Fucus [41,42,89], further progress has slowed due mainly to a lack of genomic information. Candidate genes for potential gamete recognition proteins will stimulate further molecular analysis (e.g. the Sig gene family) in the context of speciation, one of the primary motivations for this study. Diversification within the genus Fucus began fairly recently, and is ongoing [21,90]. While barriers to interspecific fertilization between more distantly-related members operate under normal conditions [91], historical and/or ongoing hybridization has been inferred in several studies [22-25,92]. Species complexes where barriers to hybridization range from ecological factors [24,30] to (potential) divergence in gamete recognition proteins promise insight into the evolutionary processes underlying species divergence.

\section{Conclusions}

Our study compares gender-specific sexual and vegetative transcriptional profiles in an oogamous brown alga, providing the first large scale transcriptomic dataset for fucoid seaweeds, and increases the number of annotated mRNA sequences in $F$. vesiculosus to over 17,000 from the several hundred available previously [49]. Matches to over 3,800 unique protein accessions were identified against the only sequenced brown algal genome (Ectocarpus siliculosus). Transcriptomic datasets like this will be a useful contribution for future annotation of the $F$. vesiculosus genome (http://www.cemeb.science.gu.se/research/imago-marinegenome-projects/).

Male, but not female, reproductive tissue over-expressed cell cycle and meiotic pathways relative to vegetative tissue, as well as several genetic information processing pathways that reflect increased replicative activity associated with sperm production. At the same time, energy and carbon metabolism pathways were down-regulated in reproductive tissue, again most strongly in males. As suggested by these results at the systems-level, orthology- 
based analysis showed that 1) the number of sex-biased genes was ca. three-fold higher in male compared with female reproductive tissue, and that 2) the average expression level of male-biased genes was greater than femalebiased genes. These observations support the contention that males express a wide array of genes regulating male fitness, and agree with similar observations in metazoan models, where greater transcriptional rates in the male germline, functional (pleiotropic) constraint in females, or male competition have been suggested as possible drivers $[4,17]$.

A major aim was to identify candidate sex-biased genes with potential sexual and reproductive functions. Femalebiased candidate genes were limited to carbohydratemodifying enzymes with likely roles in cell wall/matrix modification, at least at the sequencing depth employed here. In contrast, a variety of male-specific transcripts were identified related to development, signalling and signal perception, and potential flagella-localized proteins (potential candidate gamete-recognition proteins). Taken together, this study provides a valuable addition to the scarce genomic resources available in brown algae, and a starting point for future studies of possible mechanisms underlying prezygotic isolation in this system, a first step contributing to species divergence.

\section{Additional files}

Additional file 1: Fucus vesiculosus. Image of an $F$ vesiculosus specimen with indication of the reproductive and non-reproductive tips, line drawing of female conceptacle and contents.

Additional file 2: Schematic outline of sequence processing and analysis workflow. Flow-diagram showing the workflow for sequence quality assessment, assembly, annotation, and simple database structure.

Additional file 3: Scatter plots comparing gene expression at minimum (spring tide) and maximum (neap tide) reproductive phases. Each point represents a $F$. vesiculosus gene orthologue defined by mapping contigs to the E. siliculosus proteome using BLASTX. Genes with statistically significant differences in expression between reproductive phases in a) vegetative tissue are shown by green points, and $b$ ) in male tissue by blue points (Fisher's exact tests with BenjaminiHochberg adjustment; $P<0.05$ ). Grey points indicate genes with no significant variation in expression with respect to tidal phase.

Additional file 4: Summary of KEGG annotation data per library. Summary of KEGG annotation data for Female (F), Male (M) and Vegetative (Veg) tissue; $\mathrm{S}=$ spring tide; $\mathrm{N}=$ neap tide. Values are normalized read counts; total normalized reads for the assembly are given in the last column.

Additional file 5: Summary of Pfam annotation data per library.

Summary of Pfam annotation data for Female (F) Male (M) and

Vegetative (Veg) tissue; $\mathrm{S}=$ spring tide; $\mathrm{N}=$ neap tide. Values are normalized read counts; total normalized reads for the assembly are given in the last column.

Additional file 6: Summary of KEGG pathway analysis. Summary of KEGG pathway data for Female (Fem), Male (M) and Vegetative (Veg) tissue; $\mathrm{S}=$ spring tide; $\mathrm{N}=$ neap tide.

Additional file 7: Primer sequences for qPCR analysis. Primer sequence, annotation information (NCBl accession number of Ectocarpus siliceous orthologous) and sequence description, and application size for the eight target genes studied and the two reference genes (housekeepers).

\section{Abbreviations}

SBG: Sex-biased genes; genes expressed in both sexual reproductive tissues; F: Female tissue/receptacles; M: Male tissue/receptacles; Veg: Vegetative tissue/apical tips; N: Neap tidal phase (sampling); S: Spring tidal phase (sampling); ECM: Conceptacle extra-cellular matrix; Male-biased genes: Genes up-regulated in the male tissue; Female-biased genes: Genes up-regulated in the female tissue; Male-unique: Genes expressed in the male tissue exclusively, with no identified reads in remaining tissue types analysed; Female-unique: Genes expressed in the female tissue exclusively.

\section{Competing interests}

The authors declare that they have no competing interests.

\section{Authors' contributions}

GAP designed the study. GAP and CFM sampled material in the field, CFM prepared CDNA libraries for pyrosequencing, MJFM carried out the RT-qPCR experiments. MJFM and GAP analysed the data and performed the bioinformatic analyses. MJFM and GAP drafted the manuscript and all authors contributed to editing the final version. All authors read and approved the final manuscript.

\section{Acknowledgements}

This study was funded by the project HYBRID (PTDC/MAR/108105/2008) to GAP from the Portuguese Foundation for Science and Technology (FCT) and a post-doc fellowship to MJFM (SFRH/BPD/69956/2010) by FCT. Ana A. Ramos is acknowledged for technical help. We also gratefully acknowledge Cymon Cox for computing resources and bioinformatic assistance. We thank two anonymous reviewers for their helpful comments and suggestions.

Received: 16 January 2013 Accepted: 25 April 2013

Published: 1 May 2013

\section{References}

1. Parisi M, Nuttall R, Edwards P, Minor J, Naiman D, Lü J, Doctolero M, Vainer M, Chan C, Malley J, Eastman S, Oliver B: A survey of ovary-, testis-, and soma-biased gene expression in Drosophila melanogaster adults. Genom Biol 2004, 5:R40.

2. Singh RS, Kulathinal RJ: Male sex drive and the masculinization of the genome. BioEssays 2005, 27:518-525.

3. Eads BD, Colbourne JK, Bohuski E, Andrews J: Profiling sex-biased gene expression during parthenogenetic reproduction in Daphnia pulex. BMC Genomics 2007, 8:464.

4. Ellegren $\mathrm{H}$, Parsch J: The evolution of sex-biased genes and sex-biased gene expression. Nat Rev Genet 2007, 8:689-698,

5. Lessios HA: Reproductive isolation between species of sea urchins. Bull Mar Sci 2007, 81:191-208.

6. Gempe T, Beye M: Function and evolution of sex determination mechanisms, genes and pathways in insects. Bioessays 2010, 33:52.60.

7. Edward DA, Chapman T: The evolution and significance of male mate choice. Trends Ecol Evol 2011, 26:647-654.

8. Butlin R, Debelle A, Kerth C, Snook RR, Beukeboom LW, Cajas RFC, Diao W, et al: What do we need to know about speciation? Trends Ecol Evol 2012, 27:27-39.

9. Swanson WJ, Vacquier VD: The rapid evolution of reproductive proteins. Nat Genet 2002, 3:137-144.

10. Qvarnström A, Bailey Rl: Speciation through evolution of sex-linked genes. Heredity 2009, 102:4-15.

11. Palumbi SR: Speciation and the evolution of gamete recognition genes: pattern and process. Heredity 2009, 102:66-76.

12. Funk DJ, Nosil P, Etges WJ: Ecological divergence exhibits consistently positive associations with reproductive isolation across disparate taxa. Proc Natl Acad Sci USA 2006, 103:3209-3213.

13. Schluter D: Ecology and the origin of species. Trends Ecol Evol 2001, 16:372-381.

14. Orr HA: The genetic basis of reproductive isolation: insights from drosophila. Proc Natl Acad Sci USA 2005, 102:6522-6526.

15. Mank JE, Hultin-Rosenberg L, Axelsson E, Ellegren H: Rapid evolution of female-biased, but not male-biased, genes expressed in the avian brain. Mol Biol Evol 2007, 24:2698-2706.

16. Mank JE, Ellegren $\mathrm{H}$ : Sex-linkage of sexually antagonistic genes is predicted by female, but not male, effects in birds. Evol 2009, 63:1464-1472. 
17. Zhang Y, Sturgill D, Parisi M, Kumar S, Oliver B: Constraint and turnover in sex-biased gene expression in the genus Drosophila. Nature 2007, 450:233-237.

18. Mank JE, Hultin-Rosenberg L, Zwahlen M, Ellegren H: Pleiotropic constraint hampers the resolution of sexual antagonism in vertebrate gene expression. Am Nat 2008, 171:35-43.

19. Assis R, Zhou Q, Bachtrog D: Sex-biased transcriptome evolution in Drosophila. Genom Biol Evol 2012, 4:1189-1200.

20. Cock JM, Sterck L, Rouzé P, Scornet D, Allen AE, Amoutzias G, Anthouard V Artiguenave F, Aury J-M, Badger JH, Beszteri B, Billiau K, Bonnet E, Bothwell JH, Bowler C, Boyen C, Brownlee C, Carrano CJ, Charrier B, Cho GY, Coelho SM, Collén J, Corre E, Da Silva C, Delage L, Delaroque N, Dittami SM, Doulbeau S, Elias M, Farnham G, et al: The Ectocarpus genome and the independent evolution of multicellularity in brown algae. Nature 2010, 465:617-621.

21. Cánovas FG, Mota CF, Serrão EA, Pearson GA: Driving south: a multi-gene phylogeny of the brown algal family Fucaceae reveals relationships and recent drivers of a marine radiation. BMC Evol Biol 2011, 11:371.

22. Engel CR, Daguin C, Serrão EA: Genetic entities and mating system in hermaphroditic Fucus spiralis and its close dioecious relative $F$. vesiculosus (Fucaceae, Phaeophyceae). Mol Ecol 2005, 14:2033-2046.

23. Billard E, Serrão EA, Pearson GA, Engel CR, Destombe C, Valero M: Analysis of sexual phenotype and prezygotic fertility in natural populations of Fucus spiralis, F. vesiculosus (Fucaceae, Phaeophyceae) and their putative hybrids. Eur J Phycol 2005, 40:397-407.

24. Billard E, Serrão E, Pearson G, Destombe C, Valero M: Fucus vesiculosus and spiralis species complex: a nested model of local adaptation at the shore level. Mar Ecol Prog Ser 2010, 405:163-174.

25. Zardi Gl, Nicastro KR, Canovas F, Ferreira Costa J, Serrão EA, Pearson GA: Adaptive Traits Are Maintained on Steep Selective Gradients despite Gene Flow and Hybridization in the Intertidal Zone. PLoS One 2011, 6:e19402.

26. Palumbi SR: Marine speciation on a small planet. Trends Ecol Evol 1992, 7:114-118

27. Palumbi SR: Genetic divergence, reproductive isolation, and marine speciation. Annu Rev Ecol Syst 1994, 25:547-572.

28. Levitan DR, Fukami H, Jara J, Kline D, McGovern TM, McGhee KE, Swanson CA, Knowlton N: Mechanisms of reproductive isolation among sympatric broadcast-spawning corals of the Montastraea annularis species complex. Evolution 2004, 58:308-323.

29. Ladah LB, Feddersen F, Pearson GA, Serrão EA: Egg release and settlement patterns of dioecious and hermaphroditic fucoid algae during the tidal cycle. Mar Biol 2008, 155:583-591.

30. Monteiro CA, Serrão EA, Pearson GA: Prezygotic barriers to hybridization in marine broadcast spawners: reproductive timing and mating system variation. PLoS One 2012, 7:e35978.

31. Vacquier VD: Evolution of gamete recognition proteins. Science 1998 281:1995-1998.

32. Lessios HA: Speciation genes in free-spawning marine invertebrates. Integr Comp Biol 2011, 51:456-466.

33. Serrão EA, Pearson G, Kautsky L, Brawley SH: Successful externa fertilization in turbulent environments. Proc Natl Acad Sci USA 1996, 93:5286-5290.

34. Pearson GA, Brawley SH: A model for signal transduction during gamete release in the fucoid alga Pelvetia compressa. Plant Physiol 1998, 118: 305-313.

35. Pearson GA, Serrão EA, Brawley SH: Control of gamete release in fucoid algae: sensing hydrodynamic conditions via carbon acquisition. Ecology 1998, 79:1725-1739.

36. Speransky W, Brawley SH, McCully ME: Ion fluxes and modification of the extracellular matrix during gamete release in fucoid algae. J Phycol 2001 37:555-573.

37. Pearson GA, Serrão EA: Revisiting synchronous gamete release by fucoid algae in the intertidal zone: fertilization success and beyond? Integr Comp Biol 2006, 46:587-597.

38. Brawley SH: Fertilization in natural populations of the dioecous brown algal Fucus ceranoides and the importance of the polyspermy block. Mar Biol 1992, 113:145-157.

39. Pearson GA, Brawley SH: Reproductive ecology of Fucus distichus (Phaeophyceae): an intertidal alga with successful external fertilization. Mar Ecol Prog Ser 1996, 143:211-223.
40. Berndt M, Callow J, Brawley S: Gamete concentrations and timing and success of fertilization in a rocky shore seaweed. Mar Ecol Prog Ser 2002, 226:273-285.

41. Bolwell GP, Callow JA, Callow ME, Evans LV: Fertilization in brown algae. II. Evidence for lectin-sensitive complementary receptors involved in gamete recognition in Fucus serratus. J Cell Sci 1979, 36:19-30.

42. Bolwell GP, Callow JA, Evans LV: Fertilization in brown algae. III. Preliminary characterization of putative gamete receptors from eggs and sperm of Fucus serratus. J Cell Sci 1980, 43:209-224.

43. Pearson $\mathrm{G}$, Lago-Leston $\mathrm{A}$, Valente $\mathrm{M}$, Serrão E: Simple and rapid RNA extraction from freeze-dried tissue of brown algae and seagrasses. Eur J Phycol 2006, 41:97-104.

44. Schmieder R, Edwards R: Quality control and preprocessing of metagenomic datasets. Bioinformatics 2011, 27:863-864.

45. Chevreux B, Pfisterer T, Drescher B, Driesel AJ, Müller WEG, Wetter T, Suhai S: Using the miraEST assembler for reliable and automated mRNA transcript assembly and SNP detection in sequenced ESTs. Genome Res 2004, 14:1147-1159.

46. Romualdi C, Bortoluzzi S, D'Alessi F, Danieli GA: IDEG6: a web tool for detection of differentially expressed genes in multiple tag sampling experiments. Physiol Genomics 2003, 12:159-162.

47. Benjamini $Y$, Hochberg $Y$ : Controlling the false discovery rate: a practical and powerful approach to multiple testing. J R Stat SoC B 2003, 57:289-300.

48. Saeed Al, Sharov V, White J, Li J, Liang W, Bhagabati N, Braisted J, Klapa M, Currier T, Thiagarajan M, Sturn A, Snuffin M, Rezantsev A, Popov D, Ryltsov A, Kostukovich E, Borisovsky I, Liu Z, Vinsavich A, Trush V, Quackenbush J: TM4: a free, open-source system for microarray data management and analysis. Biotechniques 2003, 34:374-377.

49. Pearson GA, Hoarau G, Lago-Leston A, Coyer JA, Kube M, Reinhardt R, Henckel K, Serrão ETA, Corre E, Olsen JL: An expressed sequence Tag analysis of the intertidal brown seaweeds Fucus serratus (L.) and $F$. Vesiculosus (L.) (Heterokontophyta, Phaeophyceae) in response to Abiotic stressors. Mar Biotech 2010, 12:195-213.

50. Pfaffl MW, Horgan GW, Dempfle L: Relative expression software tool (REST) for group-wise comparison and statistical analysis of relative expression results in real-time PCR. Nuc Acid Res 2002, 30:e36.

51. Vandesompele J, De Preter K, Pattyn F, Poppe B, Van Roy N, De Paepe A, Speleman F: Accurate normalization of real-time quantitative RT-PCR data by geometric averaging of multiple internal control genes. Genom Biol 2002, 3:research0034.1-0034.11.

52. Surif MB, Raven JA: Exogenous inorganic carbon sources for photosynthesis in seawater by members of the Fucales and the Laminariales (Phaeophyta): ecological and taxonomic implications. Oecologia 1989, 78:97-105

53. Badger MR, Price GD: The role of carbonic anhydrase in photosynthesis. Annu Rev Plant Physiol Plant Mol Biol 1994, 45:369-392.

54. Zou D, Gao K, Xia J: Photosynthetic utilization of inorganic carbon in the economic brown alga, Hizikia fusiforme (Sargassaceae) from the South China Sea. J Phycol 2003, 39:1095-1100.

55. Nyvall P, Corre E, Boisset C, Barbeyron T, Rousvoal S, Scornet D, Kloareg B, Boyen $C$ : Characterization of mannuronan $C$-5-epimerase genes from the brown alga Laminaria digitata. Plant Physiol 2003, 133:726-735.

56. Brenchley JL, Raven JA, Johnston AM: Resource acquisition in two intertidal fucoid seaweeds, Fucus serratus and Himanthalia elongata: seasonal variation and effects of reproductive development. Mar Biol 1997, 129:367-375.

57. Cavalier-Smith T: Kingdom protozoa and its 18 phyla. Microbiol Rev 1993, 57:953-994

58. Müller DG, Falk H: Flagellar structure of the gametes of Ectocarpus siliculosus (Phaeophyta) as revealed by negative staining. Arch Mikrobiol 1973, 91:313-322.

59. Mank JE, Ellegren $\mathrm{H}$ : Are sex-biased genes more dispensable? Biol Lett 2009, 5:409-412

60. Mank JE: Sex chromosomes and the evolution of sexual dimorphism: lessons from the genome. Am Nat 2009, 173:141-150.

61. Mank JE, Nam K, Brunström B, Ellegren H: Ontogenetic complexity of sexual dimorphism and sex-specific selection. Mol Biol Evol 2010 27:1570-1578.

62. Reinke V, Smith HE, Nance J, Wang J, Van Doren C, Begley R, Jones SJ, Davis EB, Scherer S, Ward S, Kim SK: A global profile of germline gene expression in C. elegans. Mol Cell 2000, 6:605-616. 
63. Parisi M, Nuttall R, Naiman D, Bouffard G, Malley J, Eastman S, Oliver B: Paucity of genes on the drosophila $\mathrm{X}$ chromosome showing male-biased expression. Science 2003, 299:697-700.

64. Khil PP, Smirnova N, Romanienko PJ, Camerini-Otero RD: The mouse $X$ chromosome is enriched for sex-biased genes not subject to selection by meiotic sex chromosome inactivation. Nat Genet 2004, 36:642-646.

65. Sturgill D, Zhang Y, Parisi M, Oliver B: Demasculinization of $X$ chromosomes in the Drosophila genus. Nature 2007, 450:238-241.

66. Muyle A, Zemp N, Deschamps C, Mousset S, Widmer A, Marais GaB: Rapid de novo evolution of $X$ chromosome dosage compensation in Silene latifolia, a plant with young sex chromosomes. PLOS Biol 2012, 10:e1001308.

67. Zhang YE, Vibranovski MD, Landback P, Marais GAB, Long M: Chromosomal redistribution of male-biased genes in mammalian evolution with two bursts of gene gain on the X chromosome. PLOS Biol 2010, 8:e1000494.

68. Müller DG: Generationswechsel, kernphasenwechsel und sexualität der braunalge Ectocarpus siliculosus im kulturversuch. Planta 1967, 75:39-54.

69. Coelho SM, Godfroy O, Arun A, Le Corguillé G, Peters AF, Cock JM: Genetic regulation of life cycle transitions in the brown alga Ectocarpus. Plant Signal Behav 2011, 6:1858-1860.

70. Mah SA, Swanson WJ, Vacquier VD: Positive selection in the carbohydrate recognition domains of sea urchin sperm receptor for egg jelly (suREJ) proteins. Molecular Biol Evol 2005, 22:533-541.

71. Ruiz-Binder NE, Geimer S, Melkonian M: In vivo localization of centrin in the green alga Chlamydomonas reinhardtii. Cell Motil Cytoskeleton 2002, 52:43-55.

72. Gualtieri P, Robinson KR: A Rhodopsin-like protein in the plasma membrane of Silvetia compressa eggs. Photochem Photobiol 2002, 75:76-78.

73. Hurd AM: Effect of unilateral monochromatic light and group orientation on the polarity of germinating Fucus spores. Bot Gaz 1920, 70:25-50.

74. Bisgrove SR, Kropf DL: Asymmetric cell divisions: zygotes of fucoid algae as a model system. Plant Cell Monogr 2007, 9:323-341.

75. Dymek EE, Smith EF: A conserved CaM- and radial spoke associated complex mediates regulation of flagellar dynein activity. J Cell Biol 2007, 179:515-526.

76. Nolan MA, Babcock DF, Wennemuth G, Brown W, Burton KA, McKnight GS: Sperm-specific protein kinase A catalytic subunit $\mathrm{Ca}_{2}$ orchestrates CAMP signaling for male fertility. Proc Natl Acad Sci USA 2004, 101:13483-13488.

77. Visconti PE, Westbrook VA, Chertihin O, Demarco I, Sleight S, Diekman AB: Novel signaling pathways involved in sperm acquisition of fertilizing capacity. J Reprod Immun 2002, 53:133-150.

78. Burton KA, McKnight GS: PKA, germ cells, and fertility. Physiol 2007, 22:40-46.

79. Darszon A, Nishigaki T, Beltran C, Treviño CL: Calcium channels in the development, maturation, and function of spermatozoa. Physiol Rev 2011, 91:1305-1355.

80. Collingridge PW, Wheeler G, Brownlee C: The molecular mechanisms of calcium signalling in Chlamydomonas flagella. Cilia 2012, 1:P19.

81. Smith EF: Regulation of flagellar dynein by calcium and a role for an axonemal calmodulin and calmodulin- dependent kinase. Mol Biol $\mathrm{Cell}$ 2002, 13:3303-3313.

82. Marín-Briggiler Cl, Jha KN, Chertihin O, Buffone MG, Herr JC, Vazquez-Levin $\mathrm{MH}$, Visconti PE: Evidence of the presence of calcium/calmodulindependent protein kinase IV in human sperm and its involvement in motility regulation. J Cell Sci 2005, 118:2013-2022.

83. Morita M, Iguchi A, Takemura A: Roles of calmodulin and calcium/ calmodulin-dependent protein kinase in flagellar motility regulation in the coral Acropora digitifera. Mar Biotech 2009, 11:118-123.

84. Nakagami $\mathrm{H}$, Pitzschke A, Hirt $\mathrm{H}$ : Emerging MAP kinase pathways in plant stress signalling. Trend Plant Sci 2005, 10:339-346.

85. Berman SA, Wilson NF, Haas NA, Lefebvre PA: A Novel MAP Kinase regulates flagellar length in Chlamydomonas. Curr Biol 2003, 13:1145-1149.

86. Armbrust EV: Identification of a new gene family expressed during the onset of sexual reproduction in the centric diatom Thalassiosira weissflogii. Appl Environ Microbiol 1999, 65:3121-3128.

87. Campbell ID, Bork P: Epidermal growth factor-like modules. Curr Opin Struct Biol 1993, 3:385-392

88. Davis CG: The many faces of epidermal growth factor repeats. New Biol 1990, 2:410-419.

89. Jones JL, Callow JA, Green JR: Monoclonal antibodies to sperm surface antigens of the brown alga Fucus serratus exhibit region-, gamete-, species- and genus-preferential binding. Planta 1988, 176:298-306.
90. Pereyra RT, Bergström L, Kautsky L, Johannesson K: Rapid speciation in a newly opened postglacial marine environment, the Baltic Sea. BMC Evol Biol 2009, 9:70.

91. Bolwell GP, Callow JA, Callow ME, Evans LV: Cross-fertilisation in fucoid seaweeds. Nature 1977, 268:626-627.

92. Neiva J, Pearson GA, Valero M, Serrão EA: Surfing the wave on a borrowed board: range expansion and spread of introgressed organellar genomes in the seaweed Fucus ceranoides L. Mol Ecol 2010, 19:4812-4822.

doi:10.1186/1471-2164-14-294

Cite this article as: Martins et al:: Sex-biased gene expression in the brown alga Fucus vesiculosus. BMC Genomics 2013 14:294

\section{Submit your next manuscript to BioMed Central and take full advantage of:}

- Convenient online submission

- Thorough peer review

- No space constraints or color figure charges

- Immediate publication on acceptance

- Inclusion in PubMed, CAS, Scopus and Google Scholar

- Research which is freely available for redistribution
C Biomed Central 